\title{
Transient Stability Improvement using FACTS Devices
}

\author{
Pradeepkumar S. Mahapure ${ }^{1}$, A. R. Soman ${ }^{2}$ \\ ${ }^{1}$ Bharati Vidyapeeth College of Engineering, Pune, India \\ ${ }^{2}$ Assistant Professor, Bharati Vidyapeeth College of Engineering, Pune, India
}

\begin{abstract}
FACTS devices used in electrical systems form one of the important aspects of power electronics revolution that are taking place in electrical areas. Use of several Technological FACTS devices in Electrical power system is because of advanced researches in power electronics. This revolution in power electronics is happening and different applications in electronic system will tend to expand and increase day by day. Almost unique and ideal quality and properties of FACTS controllers that is possible to implement so to improve transient and overall stability of Electrical network, as when using these controllers it allows to have control on network conditions by giving quick response in less time by control on reactive energy which will further result in enhancement of electric energy. Stability in System and operation in electrical power systems during huge disturbances and faults can be obtained by maintaining Transient stability as Transient stability control plays important role in control of power system parameters. By employing UPFC in network it plays an important role as it acts as effective FACTS (Flexible AC Transmission System) equipment. It is possible to obtain control on the true or real, reactive energy flowing along network through changing accordingly series and shunt values, and when FACTS devices are attached with On Site Generation (ONG) or Decentralised energy by connecting it using DC link to obtain control on disturbances created during or by faults results in improvement of overall stability of a electrical network. To show different capabilities of UPFC study of collection of overall performance characteristics is presented. Different FACTS controllers can be used are Static Synchronous Series Compensator (SSSC), Thyristor Controlled Series Capacitor (TCSC), and Static VAR Compensator (SVC) respectively are compared with UPFC and performance of UPFC against other FACTS controller is checked.
\end{abstract}

Keywords: SVC, STATCOM, Transient Stability, UPFC

\section{Introduction}

Recent electrical network acts as large complicated system containing of huge numbers of generators from generating stations, transmission line network, different types of loads and transformers. Most of transmission lines are loaded more than that of the designed capacity or that of the built capacity when they were erected. Considering future increasing power demand and in case of a major fault occurring in lines of system, the issues of transient stability will result in limiting factor for transmission system. Due to blackout in many countries it happened because of collapse in system so now electrical power engineers are designing a system which will be much more reliable and will look into stability issues and will operate for maintaining system stable. In case of different huge faults in system such as ground faults, shortcircuit faults within different phases, open circuit faults or On/Off operation of lines, overall synchronism in system and its stability depend upon the operating conditions and loading of system so as continue synchronous operation in the system throughout. Stability of system is governed by three factors i.e. initial stages in system, occurrence in fault or type of fault and the severity of that fault. Recent researches and designs in electronic circuitry introduce different FACTS controllers (flexible ac transmission system) such as SSSC, TCSC, SVC and UPFC in power systems. Employing various FACTS equipments in transmission network helps to control different network parameters in limited period and this property of FACTS controllers is utilised in maintaining electrical power system stability of a complicated electrical network. It makes possible the increased utilization of present electrical equipments i.e. transmission lines, transformers etc and load these equipments close to its capacity and hence preventing from building new electrical network.

Static VAR Compensator (SVC) is one of the FACTS devices of initial stage that can improve the system voltage profile by control of voltage at any of the required bus. Reactive power management (can be obtained by changing firing angle of thyristors at required ratio) is the first job of SVC that helps to have required voltage level at particular required bus. SVCs are compared with classical shunt compensation that has been implemented so to gain high characteristic voltage control. To reduce electrical swings in network, decrease losses through management in reactive power, SVCs are implemented.

TCSC is the other device in FACTS controller series that is increasingly used in different power sectors in electrical networks. Controlling, maintaining and scheduling electrical energy flow, gaining reduction in unsymmetrical components, reduction in the total system loss, obtaining good system profile, controlling fault currents, mitigating sub synchronous resonance (SSR), reduction in oscillations of power swings also improving overall stability this states that TCSC can operate in different modes for control of electrical network.

The SSSC is another important device of controller series. Operation of Synchronous generator without using any external sources also known as series compensator which gives output as voltage and further in quadrature with line current, further are controllable and independent of this line current so that to increase or decrease overall reactive voltage drop along transmission lines and hence thus obtaining control on flow of electrical energy. Basic use of SSSC is 


\section{International Journal of Science and Research (IJSR) \\ ISSN (Online): 2319-7064}

Index Copernicus Value (2013): 6.14 | Impact Factor (2015): 6.391

gaining controlled flow of power in steady state in transmission lines so that it can help in improving of overall system stability of electrical network.

Improvement in steady state stability, dynamic stability and transient stability which further result in improvement in overall system stability that can be obtained using UPFC which forms most variant devices among all available FACTS controller or FACTS family series. UPFC includes both Static Synchronous Compensator (STATCOM) and SSSC hence it becomes possible to have control on many values independently as per required ratio. The different properties of all these Controllers give an alternate way in gaining control over transmission voltage level, impedance and angle of system independently or selectively, or also other alternative of gaining real, reactive power flow control along transmitting lines. Matlab/Simulink model is designed by application of UPFC controllers for the two-area power system and transient stability performance can be evaluated also actual operation and performance of UPFC is compared with other FACTS devices.

Large signal stability puts limit on long transmission lines for carrying power or results in limit on power transfer capability of system. Huge initial cost for erection of long transmission lines and total tariff of supplying the additional power, are the Economic factors that gives strong incentives for exploring all economic and technically feasible by increasing stability limit. Another side shows that, design of different alternate methods to employ transmission lines at its best maximum thermal capacity had resulted in more attention research in coming periods. Using UPFC we have an approach or view towards stability problem or solving firstswing stability problem, using comprehensive analysis. Using UPFC we can have different benefits in the control policies i.e. at first, using the local variable of system also at second, ensures good possible stability control in view of other existing methods. It becomes easy to obtain huge improvement in the transient stability by mitigating the active and reactive powers.

\section{Flexible Ac Transmission Devices}

Day by day there is increase in electrical power demand and in order to fulfil these needs and demands electrical network is used near or even beyond its thermal loading limit i.e. these transmission lines operate with $100 \%$ efficiency. Thus, because of this loading of transmission lines fault free working in electrical system and reliability in supply is in vicinity of high risks for faults. By considering all other factors such as environmental, economical and feasible reasons the construction of additional transmission lines and other network becomes difficult. This gives rise to power electronics technology of FACTS devices.

The flow of electricity in the neighbouring parts of network is reflected or altered as voltage level at particular bus and also power flowing along lines is varied. Effect of Mutual inductance may be seen which is because of the positive influence of a single device placed in the vicinity of another. Additional preventive measures are required to be taken into consideration in operating system in other parts of the grid so as to prevent long transmission lines to become overload or that voltage values at other respective buses rise to unacceptable values.

Reducing active and total power losses, preventing overloading of network also maintaining system bus voltages within acceptable range or near its reference values are resulting objective functions for using FACTS devices in electrical system. A certain part of the objective factors depends upon particular equipments in FACTS family which makes possible for influencing certain parameter in grid.

\section{a) Identification of FACTS Projects}

- Having detail and deep studies of network \& to determine the dangerous situations or connections in system. All network situations will show all possible risks of all voltage problems such as voltage transients, voltage collapse, voltage swings, unwanted power flows, also magnitude for power swings.

- The system with stablity, that is grid operating without any faults and with high efficiency, the optimum utilization of electrical network e.g. increasing the energy transfer capacity of transmission lines could be calculated.

- The proper and appropriate selection of FACTS controller and rating for these controllers is calculated depending upon its potential depending upon power transfer capability of transmission network.

- A comparative study can be made between all FACTS devices so that to carry comparison between all types and its operations and its conventional solutions so that to gain achievable benefits depending upon the technical information.

\section{b) Two Area Power System Model}

Considering a model employing two areas system which forms a connection between Area- 1 and Area- 2 using a single circuit long transmission line with series FACTS controller shown in below Figure also shunt FACTS devices shown in Figure.2.

\section{Sending end}

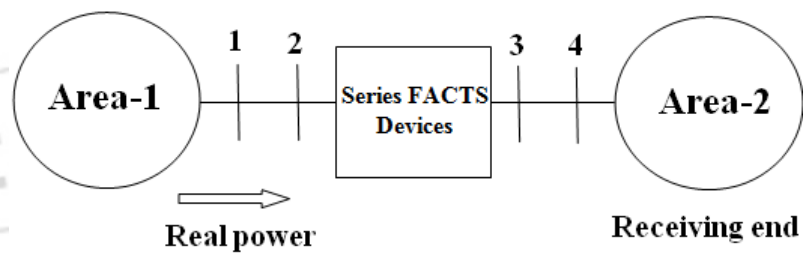

Figure 1: Model with two areas using series connection of FACTS equipment

As shown in figure above, the series FACTS devices and single circuit transmission line forms connection between Area 1 (A-1) and Area 2 (A-2). FACTS device used is UPFC i.e. (combinable STATCOM and SSSC), SSSC, and TCSC which is connected in bus-2, bus-3.As shown in figure below shunt FACTS equipment i.e. SVC placed along bus-2 and single circuit transmission line forms connection between A1 and A-2. For this model, as shown in figures Generators namely g1, g2 placed in A-1 and Generators g3, g4 placed at A-2. In both cases real power goes from A-1 to A-2. 


\section{International Journal of Science and Research (IJSR)}

ISSN (Online): 2319-7064

Index Copernicus Value (2013): 6.14 | Impact Factor (2015): 6.391

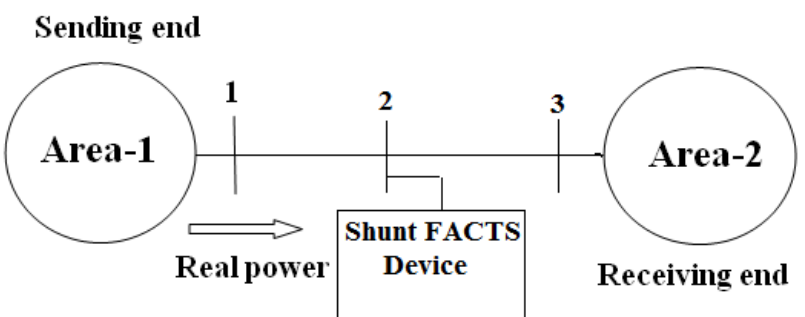

Figure.2. model with two areas using shunt connection of FACTS equipment

This model theory used in determining problems for several FACTS family members by comparing between these devices.

\section{Unified Power Flow Controller}

UPFC is versatile device amongst all FACTS controllers Three different parameters of system, such that bus voltage, line reactance, phase angle etc can be varied either individually or simultaneously and can be easily controlled using UPFC. This FACTS member has ability for adjusting and controlling these system parameters in a very simple way. A UPFC has the ability to carry out this change through controlling in-phase voltage, quadrature voltage, also by shun compensation. As shown in figure below, functional components in UPFC consist of two inverters using voltage sources (VSIs) along with common dc storage capacitance placed in between these two voltage source inverters, connection with network is made using coupling transformers. From these two inverters one VSI placed parallel in network using shunt transformers, were as another VSI connected to network using series connection via series transformer as displayed below.

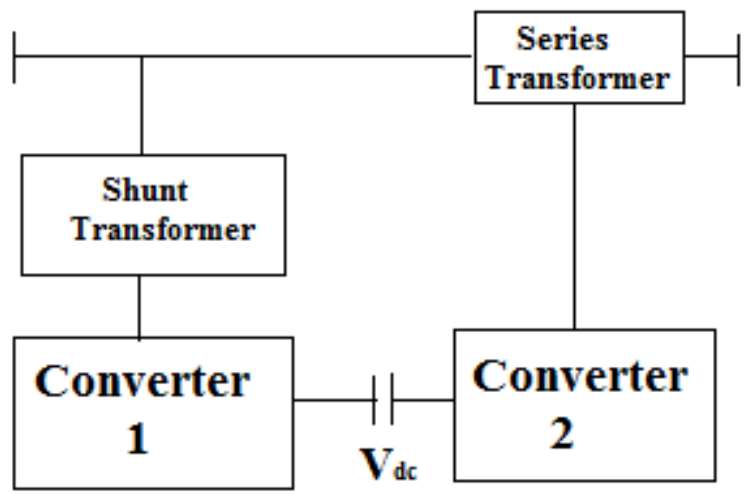

Figure 3: Basic operating model using UPFC

Selection criteria for FACTS devices, i.e. its location of placement its feedback signals of FACTS devices required to be calculated so that to have maximum benefit and effectiveness from FACTS controllers. Based on operating conditions of FACTS controllers, another important factor considered is the robustness of controllers to all variations, in all types of operating situations of power system. For this functional scheme, keeping coordination between different stabilizers is another important issue that is required to be considered it will further prevent all negative effects. Selecting a particular FACTS controller depending on its criteria is the most important issue that is taken into consideration depending upon performance and comparison. When the FACTS controller is operating in transmission system and if it is connected near heavily disturbed generator or near faulty bus, the effect on UPFC is more effective.

- Most effective and pronounced effect on UPFC is for controllers that are placed in faulty zones rather than placing these controllers away from faulty areas.

- By improvement in critical clearing time of FACTS devices i.e. UPFC and SVC it is possible to obtain improvement in transient stability.

- Reduction in initial swings using FACTS equipments it is possible to obtain improvement in transient stability.

By gaining huge information depending upon the intelligent, adaptive digital controllers from wide area measurement, control systems for these FACTS equipments are designable. Network systems employing FACTS equipments, high level damping cannot form safety side operating designs for maximum areas controlling. Else providing proper and adequate damping for wide ranging of operating conditions will form most reliable criteria that are to be fulfilled. To maintain and ensure security in operation in power system network the coordination between the different controllers in same network also in nearby network is to be determined on large also managed properly. Four different FACTS equipments operated, executed also compared, namely SVC, STATCOM, SSSC, and UPFC. Critical clearing time (CCT) can be defined by the effect of operation of different FACTS controllers. The only consideration of maximizing the CCT depends upon parameters of selected FACTS controller.

\section{Conclusion}

Employing various FACTS family members in electrical network, electrical system stability can be improved by using 2-area power system theories, which is presented also discussed. Firstly by considering major disturbances or critical conditions because of occurrence of any fault, behaviour of electrical network is compared with and without presence of UPFC in this network. And secondly, characteristics of UPFC i.e. operation, performance for improvement of power system stability is compared with the other FACTS controller such as SVC, TCSC, and SSSC respectively and improvement in operations of UPFC with all devices of FACTS controllers is analysed. The results shown by STATCOM are better and give good performance than SVC among all shunt controllers. The TCSC gives greater reliability for control of flow of power in the transmission lines hence it acts as more pronounced against all shunt devices. The UPFC has many positive features against all FACTS controllers i.e. it gives independent control over the bus voltage and the line active and reactive power flows hence it is the best controller.

This FACTS family member has been designed so that it can be proposed and used to obtain control on both active and reactive power flows in the transmission line also to regulate the voltage bus also maintaining power quality and stability in system so that to ensure the continuity of electricity supply in the system. Thus this device i.e. UPFC produces a huge impact on stability enhancement of power system and resulting in loading these transmitting lines near to its thermal capability. Hence these FACTS controller gives system operators large range and great flexibility to satisfy 


\section{International Journal of Science and Research (IJSR) \\ ISSN (Online): 2319-7064}

Index Copernicus Value (2013): 6.14 | Impact Factor (2015): 6.391

the needs of consumer fulfil their demands that the deregulated power system imposes.

\section{References}

[1] C. Schauder, L. Gyugyi, M. Lund, D. M. Hamai T. R. Rietman, D. Torgerson "Operation Of the Unified Power Flow Controller (UPFC) Under practical constaints" IEEE Transactions on Power Delivery, Vol. 13, No. 2, April 1998.

[2] B. Renz, A. Keri, C. Schauder, E. Stacey, A. S. Mehraban L. Kovalsky, L. Gyugyi A. Edris "AEP UNIFIED POWER FLOW CONTROLLER PERFORMANCE" IEEE Transactions on Power Delivery, Vol. 14, No. 4, October 1999.

[3] L.Dong L., Zhang M. L. Crow “A New Control Strategy for the Unified Power Flow Controller”IEEE-2002.

[4] Eskandar Gholipour and Shahrokh Saadate, "Improving of Transient Stability of Power Systems Using UPFC" IEEE Transactions on Power April 2005.

[5] A.Elkholy F. Fahmy A. Abou El-Ela, "Power System Stability Enhancement using The Unified Power Flow Controller" Proceedings of $14^{\text {th }}$ International Middle East Power Systems Conference, Cairo University, December 2010.

[6] K. Manoz kumar Reddy "Improving the Transient and Dynamic stability of the Network by Unified Power Flow Controller (UPFC)" International Journal of Scientific and Research Publications, Volume 2, Issue 5, May 2012.

[7] Reference book of Reactive Power Management by D.M.Tagare. 